\title{
Performance of Pile Cap Foundation with Respect to Cap Thickness
}

\author{
Soukayna El Hammouli ${ }^{1}$, Adel Hanna ${ }^{2}$, Lan Lin ${ }^{3}$, Mahmoud Khalifa ${ }^{4}$ \\ Concordia University \\ 1455 de Masionneuve Blvd. West, Montreal, Canada, H3G 1M8 \\ ${ }^{1}$ soukayna.elhammouli@gmail.com, ${ }^{2}$ hanna@civil.concordia.ca, ${ }^{3}$ lan.lin@concordia.ca, ${ }^{4}$ mahm_kh@encs.concordia.ca
}

\begin{abstract}
The thickness of a pile cap is a governing parameter in the design of pile-cap foundations. A thin cap perform as a flexible slab which distributes the load on the piles unevenly, and it does not accord with the concept of pile foundation design. On the other hand, a thicker and rigid cap is expected to evenly distribute the load on the piles, as well as resisting bending moments and punching shear failure, but may impose more load on the foundation compared to a thinner cap. In view of these differences, there is a need to determine how the pile cap thickness would affect the performance of piles and pile cap. For this purpose, a 3-D finite element model was developed to simulate a 16-pile cap foundation for a range of cap thickness from $0.5 \mathrm{~m}$ to $3 \mathrm{~m}$. The collected data is in the form of the load on individual piles and the deformation of the cap.
\end{abstract}

Keywords: Pile-cap, cap thickness, rigidity, load sharing, numerical modeling, ABAQUS, foundation.

\section{Introduction}

A pile cap can be either rigid or flexible. Theoretically speaking, if the pile cap is rigid enough, all the piles would be equally loaded. However, if the pile cap is flexible, then the piles close to the loading point would be over loaded compared to others. The results from previous studies have indicated that the pile cap thickness has a direct impact on the pile cap flexural rigidity, which will, in turn, affect the loads transferred from the superstructure to the substructure. Researchers have developed some formulae to determine the rigidity of the pile cap, such as Hain and Lee [1], Randolph [2], Viggiani et al. [3], etc. Very recently, Rabbany et al. [4] proposed an equation to estimate pile cap depth due to external loading. However, the results in Rabbany et al. [4] was based on a regression analysis on very limited data provided about 30 years ago in Reynolds and Steedman [5].

CSA A23.3-14 [6] provides following Clauses for design of pile caps including Clause 15.3 (Footings and pile caps supporting circular and regular polygonal columns or pedestals), Clause 15.5 (Shear design of footings and pile caps), Clause 15.6 (Development of reinforcement in footings and pile caps), Clause 15.8.3 (Minimum depth of pile caps), and Clause 15.9 (Transfer of force at base of column, pile cap, wall, or pedestal). There are two methods stipulated in CSA A23.3-14 for the design of pile caps, one is sectional method for shallow pile caps, and the other is Strut-and-Tie (STM) method for deep pile caps. Both methods follow the same procedure to determine the pile cap depth, which is the larger to satify the requirments for both one-way and two-way shear check. However, in both cases the design shear is determined by assuming the reaction in each pile due to external loading is the same, i.e., the pile reaction is obtained by using the total load in the column divided by the number of piles in the foundation. This assumption might not be vaild if the cap is not too rigid to be able to evenly distribute the load over piles, which would lead the pile cap design either unsafe or overdesigned.

Given this, the objective of this study is to examine the effects of pile cap thickness on the performance of pile foundation in terms of the load distribution on piles and the deformation of pile cap itself, and to conclude what pile cap thickness would make the loads distribute more uniformly.

\section{Development of Numerical Model}

Figure 1 illustrates the geometry configuration of the foundation under examination. The centerline of the piles is aligned in both directions. The pile cap is square with $8 \mathrm{~m}$ long which remains unchanged in all the cases for the analysis. The thickness of the pile cap $t$ is a variable, which is between $0.5 \mathrm{~m}$ and $3.0 \mathrm{~m}$. The diameter of piles is $0.5 \mathrm{~m}$, and the length is $8.5 \mathrm{~m}$. The center-to-center spacing of piles is $2.5 \mathrm{~m}$. Both pile cap and piles are made of concrete. Due to the symmetry of the foundation, only a quarter of the foundation enclosed by the shaded area in Fig. 1 was modelled and analyzd in this study, and the loads on Piles 1 to 4 were monitored in the examination. 
(a)

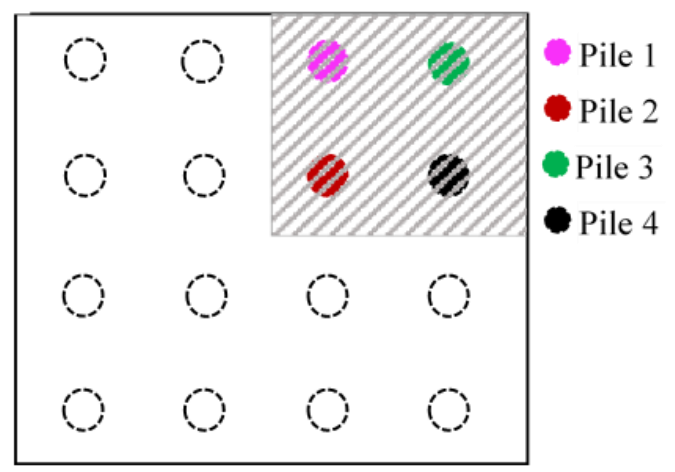

(b)

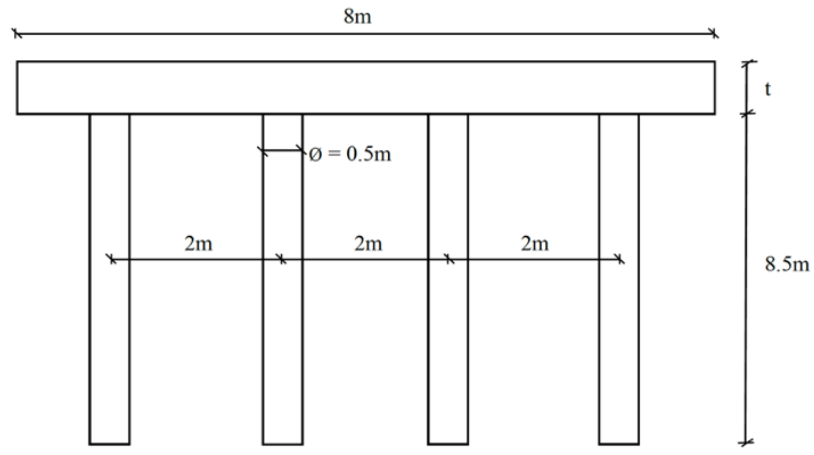

Fig.1: Geometry configuration of the foundation: (a) plan view, (b) elevation view.

The three-dimensional (3D) finite element analysis software ABAQUS was used to model the foundation. In particular, both piles and pile cap were modelled using C3D8 element. Full integration instead of reduced integration was assigned to these elements. The soil layer was modeled as an elastic-plastic constitutive model following the Mohr-Coulomb yield criterion. The soil continuum is represented by a single layer of sand with a width of $10 \mathrm{~m}$ and a length of $17 \mathrm{~m}$. Specifically, the entire width of the soil is taken as 2.5 times the width of the pile cap (i.e., $2.5 \times 8 \mathrm{~m}$ ) and the length is taken as 2 times the pile length (i.e., $2 \times 8.5 \mathrm{~m}$ ). The interaction between the pile cap foundation and the soil was simulated using surface-to-surface interaction applying slave and master concept between pile cap and soil, pile circumference

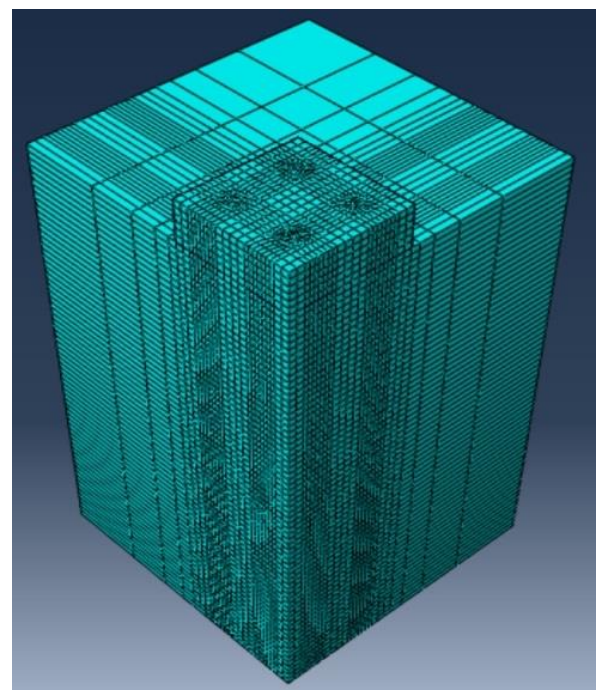

Fig. 2: ABAQUS meshing for $1 / 4$ of the 16-pile foundation.

and soil, pile tip and soil. As an illustration, Figure 2 presents the ABAQUS model meshing for a quarter of the 16-pile foundation. Figure 3 shows the boundary conditions defined in the model. In the coordinate system, the positive direction for the vertical axis $\mathrm{Z}$ is downward, the positive direction for horizontal axes $\mathrm{X}$ and $\mathrm{Y}$ follows the well-known right-hand thumb rule. The restraints for the face nodes, corner nodes and bottom nodes assigned to translation (U) and rotation (UR) about given axes are provided in Fig. 3. A detailed descriotion of the modelling can be found in EI Hammouli [7]. 


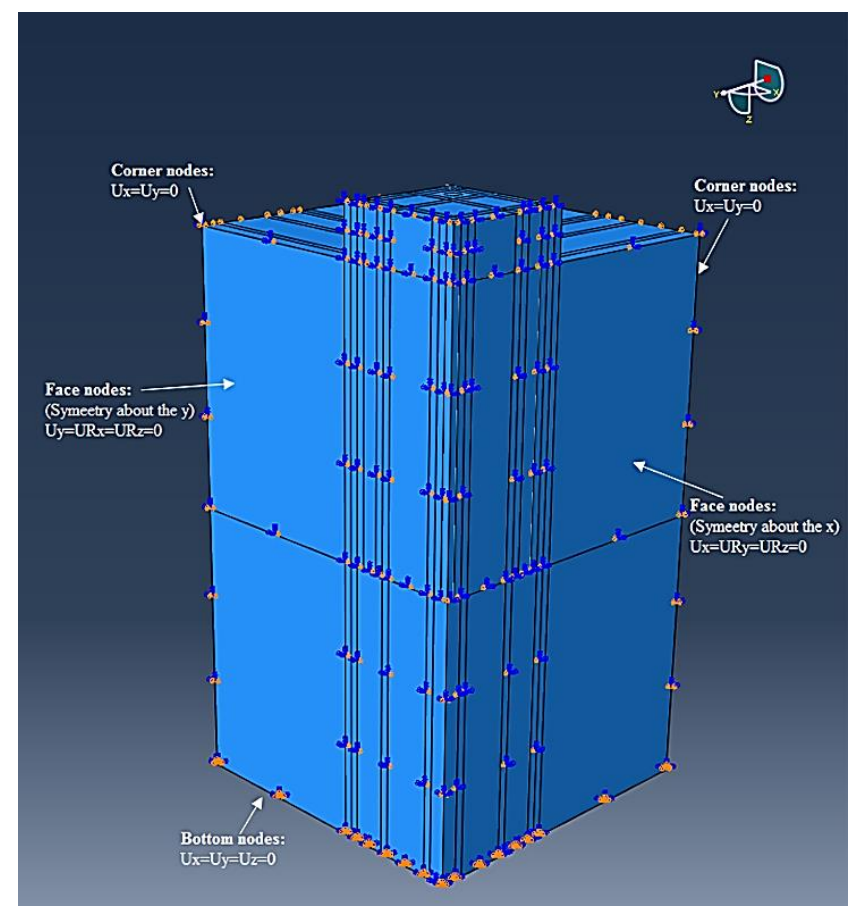

Fig. 3: Boundary conditions defined in the model.

Two soil mediums, i.e., medium sand and dense sand, are assigned to the foundation, respectively. Table 1 lists the material properties used in the analysis for both soils and concrete, such as Young's modulus of elasticity, Poisson's ratio, friction angle and dilatancy angle.

Table 1: Material properties.

\begin{tabular}{|c|c|c|c|c|}
\hline \multirow{2}{*}{ Parameter } & \multirow{2}{*}{ Symbol } & \multicolumn{2}{|c|}{ Soil } & \multirow{2}{*}{ Concrete } \\
\cline { 3 - 5 } & & Dense-sand & Medium-sand & \\
\hline Material density & $\mathrm{P}\left(\mathrm{t} / \mathrm{m}^{3}\right)$ & 1.63 & 1.49 & 2.41 \\
\hline Young's modulus & $\mathrm{E}(\mathrm{MPa})$ & 65 & 49 & 23600 \\
\hline Friction angle & $\phi\left(^{\circ}\right)$ & 40 & 30 & \\
\hline Poison's ratio & $v$ & 0.35 & 0.29 & 0.21 \\
\hline Angle of dilatancy & $\psi\left({ }^{\circ}\right)$ & 10 & 0 & \\
\hline Friction coefficient & & 0.55 & 0.45 & \\
\hline
\end{tabular}

\section{Model Validation}

In order to validate the above-mentioned techniques of developing the numerical model in this study, the results presented in Alnuiam et al. [8] and the data collected from the geotechnical centrifuge testing available in Horikoshi et al. [9] were used for model validation. Alnuiam et al. used software Plaxis to create a 3D finite element model (Fig. 4) with a configuration very similar to the one to be examined in our study (Fig. 2), in order to study the performance of pile caps in 
Toyoura sand. The material properties considered in their modelling are presented in Table 2 . They then calibrated their finite element model by centrifuge testing on an aluminum model, the input parameters for their modelling are listed in 3.

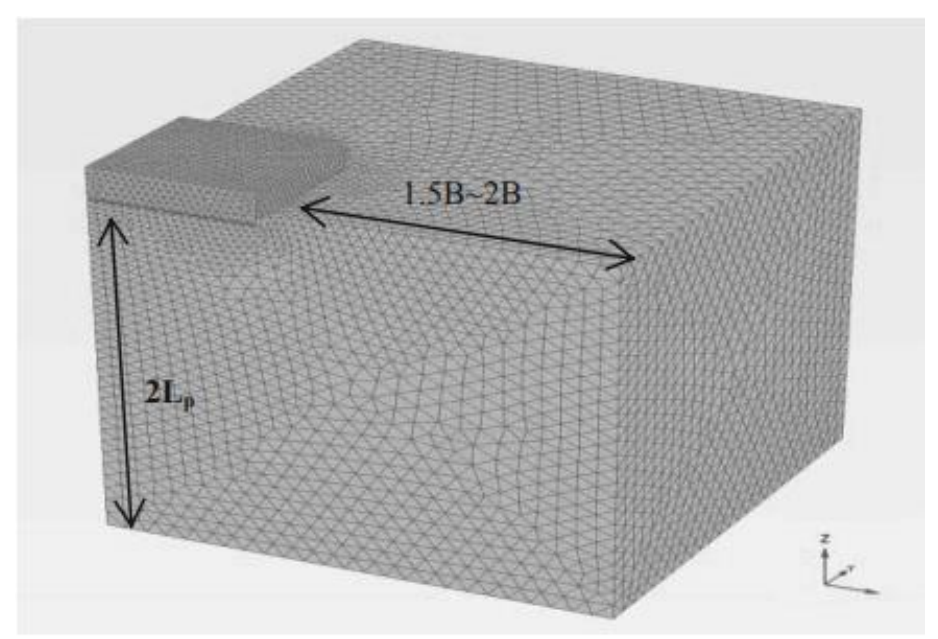

Fig. 4: Finite element model as Alnuiam et al. (2013).

Table 2: Material properties as Alnuiam et al. [8].

\begin{tabular}{|c|c|c|}
\hline Parameter & Toyoura sand & Concrete \\
\hline Constitutive modeling & Mohr-Coulomb & Linear elastic \\
\hline Unit weight $\left(\mathrm{kNm}^{3}\right)$ & 14.6 & 23.6 \\
\hline Angle of internal friction & 45 & - \\
\hline Modulus of elasticity & $4500 \mathrm{kN} / \mathrm{m}^{2}$ & $23.6 \mathrm{GN} / \mathrm{m}^{2}$ \\
\hline Poisson's ratio & 0.175 & 0.21 \\
\hline $\begin{array}{c}\text { Stiffness increases with } \\
\text { depth }\end{array}$ & Yes & No \\
\hline $\begin{array}{c}\text { Incremental modulus of } \\
\text { elasticity }\left(\mathrm{kN} / \mathrm{m}^{2}\right)\end{array}$ & 6500 & - \\
\hline Interface reduction factor & 0.43 & - \\
\hline
\end{tabular}

Table 3: Inputs for modelling as Alnuiam et al. [8].

\begin{tabular}{|c|c|c|}
\hline Parameter & Model & Prototype $(\mathrm{n}=50)$ \\
\hline Diameter $(\mathrm{mm})$ & 10 & 500 \\
\hline Wall thickness $(\mathrm{mm})$ & 1 & solid \\
\hline Material & Aluminum & Concrete \\
\hline Thickness & $170 \mathrm{~mm}$ & $8.5 \mathrm{~m}$ \\
\hline Modulus of elasticity & $71 \mathrm{GPa}$ & $41.7 \mathrm{GPa}$ \\
\hline Pile length & $40 \mathrm{~mm}$ & $2 \mathrm{~m}$ \\
\hline Raft width (square) & $80 \mathrm{~mm}$ & $4 \mathrm{~m}$ \\
\hline Pile spacing & $40 \mathrm{~mm}$ & $2 \mathrm{~m}$ \\
\hline Number of piles & 4 & 4 \\
\hline
\end{tabular}

In the process of validation, a 3D ABAQUS model was developed for the pile foundation examined by Alnuiam et al. [8] as shown in Fig. 4 using the information given in Tables 2 and 3 following the modeling techniques described above in Section 2. For ease of discussion, this model is referred to as FEM. Figure 5 presents the results of the displacement in the pile cap $v s$ the axial load from FEM superimposed with the results given in Alnuiam et al. [8] (labeled as ALN) and Horikoshi et al. [9] (Labelled as HOR). It can be seen in the figure that FEM results are very close to HOR and ALN. For example, at the load of $5000 \mathrm{kN}$, the displacement given by FEM is about $0.032 \mathrm{~m}$ while the displacement provided by both HOR and ALN is about 0.029 and $0.031 \mathrm{~m}$ respectively; at the load of $15000 \mathrm{kN}$, the displacement given by FEM is about $0.11 \mathrm{~m}$ while the displacement provided by HOR and ALN is the same, which is about $0.105 \mathrm{~m}$. 


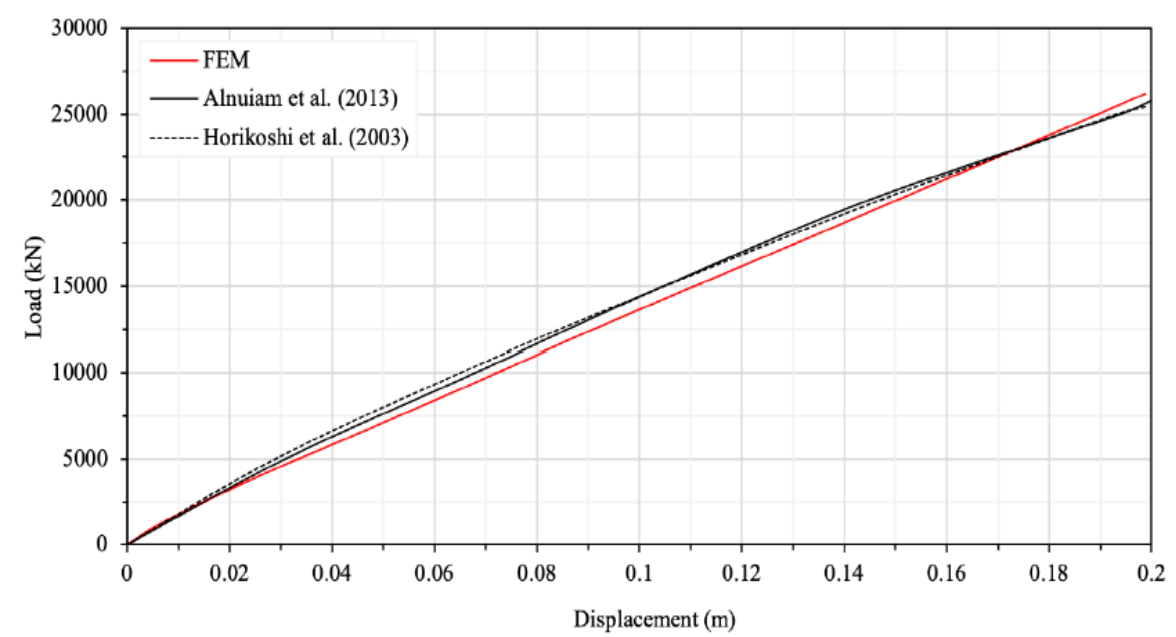

Fig. 5: Pile cap displacement vs axial loading.

\section{Results and Analysis}

In the analysis, a working load of $200 \mathrm{MN}$ was applied in the vertical direction downward at the center of the pile cap because it will cause higher deflections and deformations in both cap and piles compared to uniformly distributed vertical loading. The structural response parameters selected to examine the performance of the foundation are: pile load carried by each individual pile, and pile cap displacement in the vertical direction at selected points measured at the bottom face of the cap.

Figure 6 presents the ultimate load of each pile for different pile cap thickness varied from $0.5 \mathrm{~m}$ to $3 \mathrm{~m}$ for medium sand soil (Fig. 6a) and dense sand soil (Fig. 6b). The results in the figure clearly show that, for the thickness of $0.5 \mathrm{~m}$, Pile 2 carries the largest amount of the load followed by Piles 1 and 4 while Pile 3 carries the least. This observation is not surprising from a structural point of view as the piles close to the loading point (center piles, e.g., Pile 2) would carry more load while the piles far from the load (corner piles, e.g., Pile 3) would carry less load. More specifically, for cap thickness of $0.5 \mathrm{~m}$,

(a)

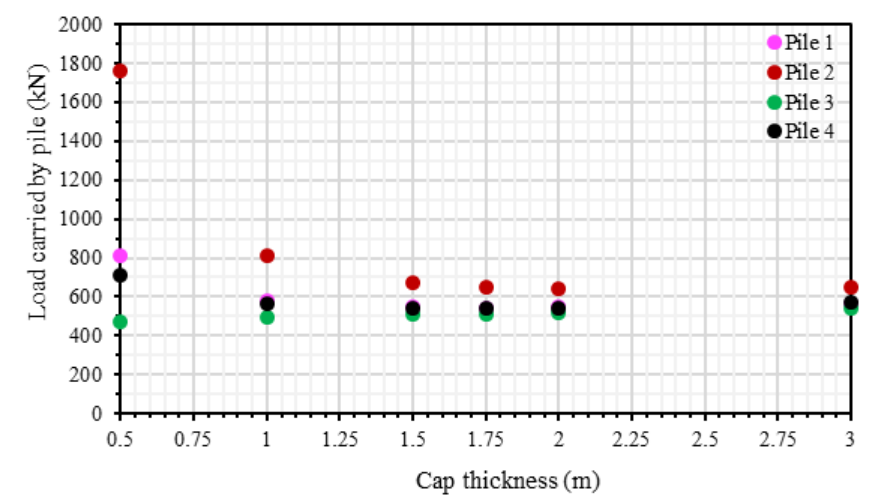

(b)

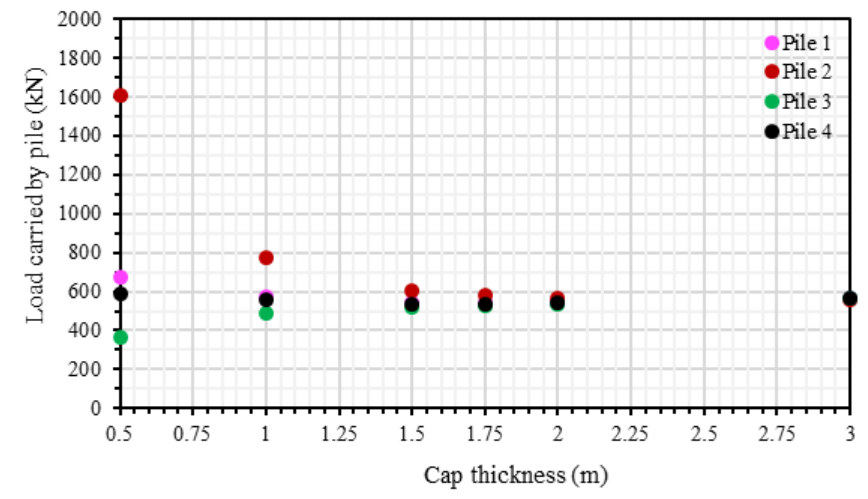

Fig. 6: Pile Load vs pile cap thickness for the 16-pile foundation: (a) medium sand soil, (b) dense sand soil.

the load resisted by Pile 2 (maximum) is 3.7 times that by Pile 3 (minimum) for the medium sand and 4.4 times for dense sand. Furthermore, as illustrated in Fig. 6 when the thickness is increased to 1m, this ratio reduces dramatically reaching around 1.6 for both soil mediums considered. When the thickness is between $1.5 \mathrm{~m}$ and $2 \mathrm{~m}$ this ratio becomes much smaller, i.e., about 1.3 for medium sand soil and 1.1for dense sand soil. As presented in Fig. 6, in dense sand soil, all 4 piles carry the same load at the thickness of $3 \mathrm{~m}$ while, in the medium sand soil, Pile 2 still carries about $20 \%$ more load than the other 
three piles. It is noteworthy that once the cap thickness is $1 \mathrm{~m}$ and above, the load distributed to Piles 1,3 and 4 is almost the same.

In addition to examining the load carried by each individual pile, the deformation of the pile cap for different cap thickness was evaluated in this study. Figure 7 illustrates the location of the selected points to be monitored in this exercise, and Figure 8 presents the deformation of these points corresponding to the cap thickness of $0.5 \mathrm{~m}$ and $3 \mathrm{~m}$ and for the medium dense sand soil. It can be seen clearly in Fig. 8 that, at the cap thickness of 3m, the points monitored undergo the same amout of the deformation. However, at the cap thickness of $0.5 \mathrm{~m}$, the center of the cap (Line 1) close to the loading point deforms more than its edge (Line 3 ). This indicates the $3 \mathrm{~m}$-deep cap is more rigid than the $0.5 \mathrm{~m}$-deep cap, which is consistent with the findings of the results shown in Fig. 6. It is also abserved in Fig. 8 that for the cap thickness of 0.5m, the deflection at point $\mathrm{C}$ is much greater than Point $\mathrm{A}$. Such a tendency is well expected in a deformed flexiable slab.

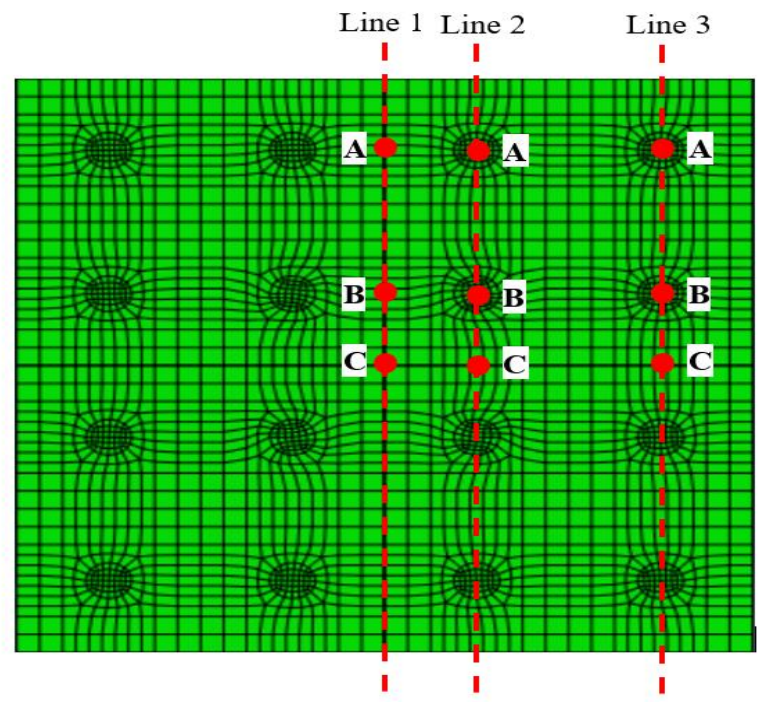

Fig. 7: Location of the points monitored.
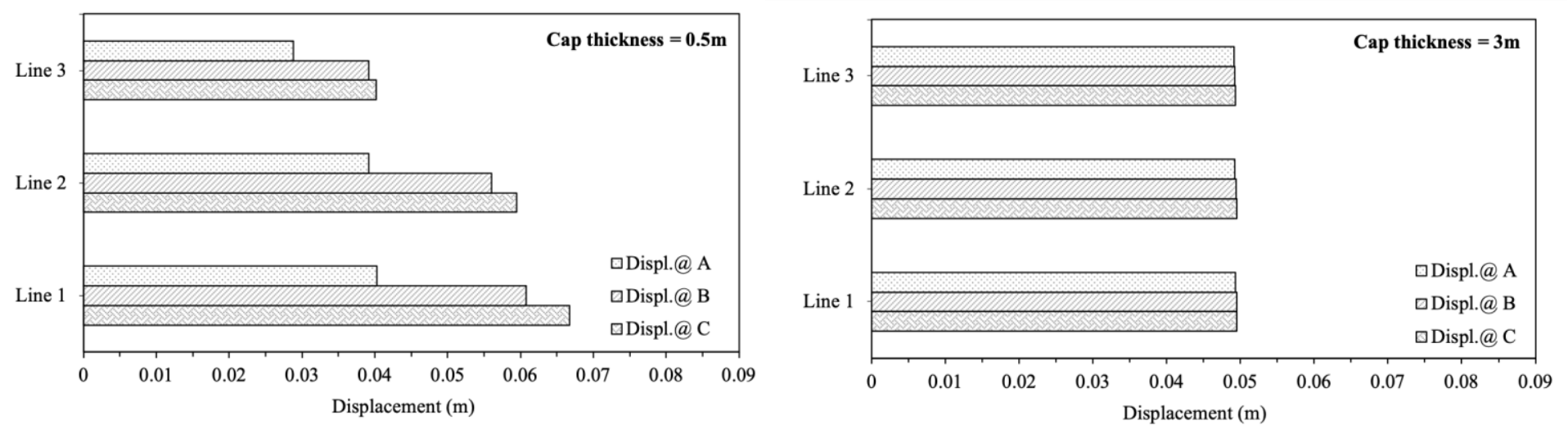

Fig. 8: Verical displacement in pile cap for a cap thickness of $0.5 \mathrm{~m}$ and $3.0 \mathrm{~m}$.

In order to conclude which cap thickness between $0.5 \mathrm{~m}$ and $3 \mathrm{~m}$ tends to lead a rigid element, results of cap curvature verse cap thickness were prepared following the approach provided in Cheng [10]. He investigated the depth of reinforced concrete rigid-pile caps for tall buildings using 3D finite element analysis. Cheng recommended using cap curvature to examine the rigidity of caps. More specifically, a pile cap would be considered rigid if a further increase in its depth will not lead to a significant reduction of the cap curvature. The so-called curvature is determined by the cap out-of-plane deflection divided by the pile spacing. Following Cheng's approach, the results of the caps investigated in 
this study are illsutrated in Fig. 9. Among the five values of the thickness tested, $1.5 \mathrm{~m}$ would be considered a threshold between a flexiable and a rigid cap. In addition, the results of the curvature corresponding to the thickness of $0.5 \mathrm{~m}$ and $1.0 \mathrm{~m}$ $1.0 \mathrm{~m}$ indicate that these two caps are very flexiable compared with others, which is consistent with the findings observed in in Figs. 6 and 8.

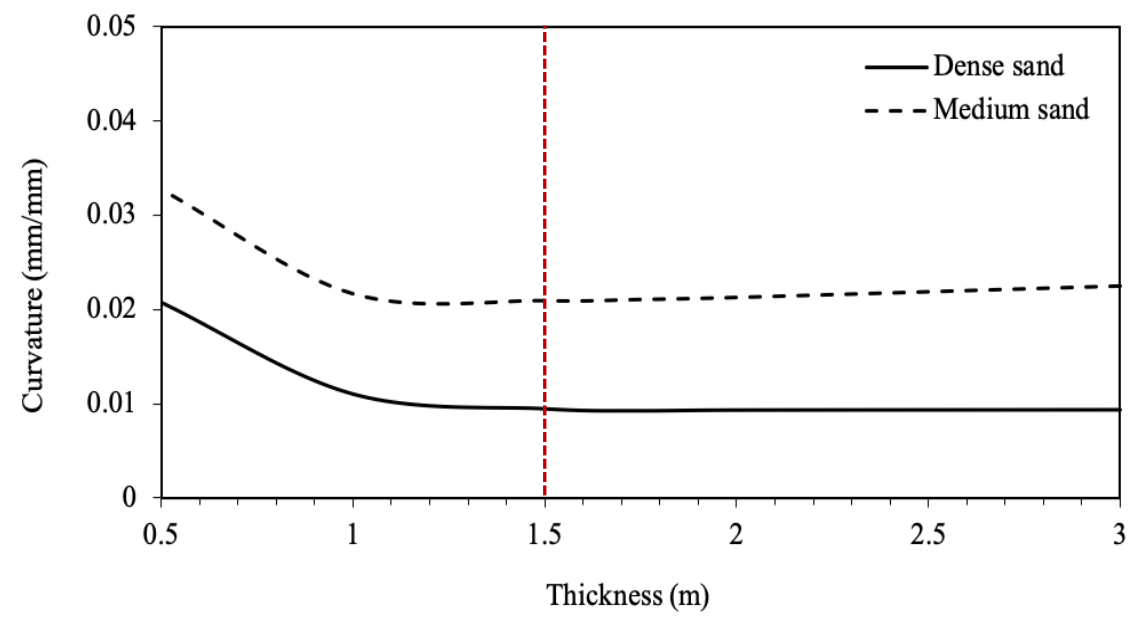

Fig. 9: Curvature vs cap thickness.

\section{Conclusion}

The effect of the cap thickness on the performance of a pile-cap foundation was investigated. A 3-D finite element model was developed using the software ABAQUS to simulate a 16-pile foundation in two soil mediums, i.e., medium dense and dense sand. The model was validated by the data available in the literature. A working load of $200 \mathrm{MN}$ was applied at the center of the cap downward. The thickness of the cap examined was betweem $0.5 \mathrm{~m}$ and $3.0 \mathrm{~m}$ with an increment of $0.5 \mathrm{~m}$. The response of the structure was evaluated by the load carried by each individual pile and the deformation of the cap. The following was concluded:

1. The pile cap is expected to be flexible for a certain thickness, beyond which the cap is to be rigid where the loads are almost distributed evenly on the piles.

2. The thickness of $1.5 \mathrm{~m}$ is recommended as a lower bond for a pile cap to be rigid among the five values of thickness examined in the study.

3. CSA A23.3-14 specifications for the design of pile caps lead to overestimating the pile cap thickness.

4. The additional load in the cap and piles due to increasing pile cap thickness is about $3 \%$ of the total load. Therefore, this extra load should not be a concern in the selection of cap thickness.

\section{References}

[1] S. Hain and I. Lee, "The analysis of flexible raft-pile systems," Géotechnique, 28(1): 65-83, 1978.

[2] M. Randolph, "Design methods for pile groups and piled rafts," Proceedings of the 13th International conference, Soil mechanics and foundation engineering, 5(13): 61-82, 1994.

[3] C. Viggiani, A. Mandolini and G. Russo, "Piles and pile foundations", New York: CRC Press, 2012.

[4] A.B. M. G. Rabbany, S. Islam and M. Hasan-Uz-Zaman, "Pile cap performances in different consequences," Architecture Research, 8(2): 51-61, 2018.

[5] C. Reynolds, and J. Steedman, "Reinforced concrete designer's handbook". London: CRC Press; $10^{\text {th }}$ edition, 1988.

[6] CSA A23.3-14, "Concrete Design Handbook," Cement Association of Canada, Ottawa, Ontario, Canada, 2014.

[7] S. EI Hammouli, "Performance of pile cap foundation with respect to cap rigidity", M.A.Sc thesis, Department of Building, Civil and Environmental Engineering, Concordia University, 2019. 
[8] Alnuiam, H. El Naggar and M. El Naggar, "Performance of Piled-Raft System under Axial Load," Proceedings of the 18th International Conference on Soil Mechanics and Geotechnical Engineering, pp. 2663-2666, 2013.

[9] K. Horikoshi, T., Matsumoto, Y., Hashizume, and T., Watanabe, "Performance of piled raft foundations subjected to static horizontal loads," International Journal of Physical Modelling in Geomechanics, 3(2): 37-50, 2003.

[10] C. Cheng, "Designing the depth of reinforced concrete rigid-pile caps for tall buildings," M.A.Sc thesis, Hong Kong University of Science and Technology, 2005. 